\title{
O aquecimento imobiliário e o mercado de habitação na área central de São Paulo (2001-2010)
}

Lucia Sbimbo. Universidade de São Paulo, São Paulo, Brasil.

RESUMO | O aquecimento imobiliário ocorrido no Brasil, desde 2006, abrangeu uma nova faixa de consumidores e novas localidades que, em período anterior, eram desvalorizadas pelo mercado. Esse fenômeno pôde ser verificado na recente dinâmica imobiliária na área central de São Paulo, em especial, nos lançamentos residenciais voltados para as faixas de renda média e média baixa, beneficiadas pela política habitacional brasileira contemporânea. A partir das informações disponibilizadas no banco de dados da Empresa Brasileira de Estudos do Patrimônio (Embraesp) e nos sites das empresas construtoras e incorporadoras, este artigo caracteriza e analisa os empreendimentos residenciais lançados na área central, entre 2001 e 2010, e problematiza a reinserção deste território no circuito imobiliário da metrópole paulistana. Diante dos resultados da pesquisa, resta a seguinte questão: como o mercado está conseguindo reproduzir o mesmo padrão nas periferias e nas áreas centrais?

PALAVRAS-CHAVE | habitação, mercado imobiliário, centros urbanos.

ABSTRACT | Since 2006, the warming in Brazilian real estate covered a range of new consumers and new locations that, in the previous period, were undervalued by the market. This phenomenon can be seen in recent real estate dynamic in the central area of São Paulo, especially in residential launches targeted to middle and lower-middle income groups, which were benefited from the contemporary Brazilian housing policy. From the information available in the database of the Empresa Brasileira de Estudos do Patrimônio (Embraesp) and the sites of construction companies and developers, this article examines the residential developments launched in the central area, between 2001 and 2010, and discusses the reintegration of this territory in the metropolitan real estate circuit. Considering the results of the survey, the question remains: how is the market reproducing the same pattern in urban outskirts and in central areas?

KEY WORDS | housing, real estate market, urban centres.

Recibido el 20 de julio de 2011, aprobado el 30 de noviembre de 2011

E-mail: Lucia Shimbo, luciazs@sc.usp.br 


\section{Introdução}

Este texto procura analisar a dinâmica imobiliária na área central da cidade de São Paulo durante a primeira década dos anos 2000. Mais precisamente, procura caracterizar o recente aquecimento do mercado de habitação e compreender os fatores que levaram ao aumento do número de lançamentos residenciais, sobretudo, voltados para os setores de renda média. Desde 2006, no Brasil, vem ocorrendo alterações significativas no seu contexto socioeconômico, na sua estrutura de financiamento habitacional e nas políticas urbanas municipais, que acabam por favorecer a atuação do mercado imobiliário em áreas e em segmentos de demanda que, até então, não eram valorizados pelos agentes privados.

A articulação entre Estado e mercado na produção e na regulação do ambiente construído é por demais potente no caso brasileiro, mas não deixa de estar presente na Europa e na América do Norte. Nesses países, como analisa Weber (2002), desde os anos 1950 estados nacionais e governos municipais desenvolveram mecanismos que tornaram o ambiente construído mais flexível e suscetível aos critérios do capital imobiliário. Na escala nacional, esses esforços incluíram recursos financeiros para a renovação urbana do pós-guerra e medidas regulatórias que facilitaram os processos de securitização de dívidas, destruíram proteções para a habitação social e proporcionaram suporte para a formação de cartéis imobiliários. Governos locais produziram seu próprio conjunto de diretivas voltadas, em sua maioria, para absorver os riscos e os custos do desenvolvimento urbano, e posterior atuação dos agentes privados que, dessa forma, não precisavam arcar com esse investimento. Em especial, nas áreas centrais consolidadas, municipalidades justificaram tais intervenções estigmatizando, estrategicamente, propriedades e imóveis que se encontravam "degradados" ou "obsoletos" e que requisitavam, portanto, iniciativas de demolição ou de reabilitação. Essas justificativas fortaleceram e naturalizaram conceitos ambíguos presentes em políticas urbanas, tais como "degradação" ou "deterioração" (em inglês, blight) e "obsolescência" (obsolescence), e que ainda criam "a aparência de certeza entre a cacofonia de demandas sobre valor da propriedade urbana" (Weber, 2002, p. 520). Para a autora, portanto, taxar alguma área como "degradada" obscurece as reais situações de determinadas propriedades, influenciando de antemão o valor e legitimando futuras intervençóes públicas e ou privadas.

Procurando escapar desse conteúdo simbólico e político do conceito de degradação, Brindley, Rydin e Stoker (1987) preferem chamar tais áreas como "negligenciadas" ou "abandonadas" (em inglês, derelict áreas), seja pelo Estado, seja pelo mercado.

Esses processos de identificação de áreas "degradadas" e os seus respectivos projetos de recuperação ou de requalificação - vale lembrar que assim como "degradação", são diversas as noçóes que dizem respeito à solução do problema, tais como, reabilitação, revitalização, regeneração etc. — também ocorreram nas grandes cidades latino-americanas, porém, com uma defasagem de tempo e com algumas características peculiares em relação às matrizes europeia e norte-americana. Na América Latina, tais processos têm fontes de recursos locais e internacionais e se baseiam, de 
modo geral, na articulação entre atores econômicos e políticos locais e nacionais para a formação de parcerias público-privadas e em modelos empresariais de gerenciamento de políticas urbanas (Zanchetti, 2010).

Por exemplo, em algumas cidades mexicanas e em São Paulo, as políticas urbanas de "revitalização" de centros, como destaca Bidou-Zachariasen (2006), inspiraram-se em modelos europeus, principalmente Barcelona, e apresentaram intenções bastante próximas, apesar de seus contextos diferentes. De modo geral, as estratégias privilegiaram a promoção de atividades econômicas ligadas ao turismo, à cultura, ao consumo de produtos de luxo bem como a requalificação de construções residenciais a fim de trazer de volta as classes médias, apesar do discurso a respeito da promoção da diversidade social. Ao retorno dessas classes "se atribuem as mudanças de imagem por que passará a cidade, o que por sua vez se acredita, irá atrair os investidores privados, sem os quais esses projetos não podem ser bem sucedidos" (Bidou-Zachariasen, 2006, p. 52).

$\mathrm{Na}$ área central da cidade de São Paulo, além de apresentar políticas e programas específicos para a sua requalificação, repercutiu também o processo nacional de aquecimento do mercado imobiliário, em especial, os lançamentos residenciais pertencentes ao "segmento econômico" que compreende os imóveis residenciais com valores de até $\mathrm{R} \$ 200.000,00$ (em reais de dezembro 2010, ou aproximadamente, cem mil dólares), destinados às famílias com renda mensal entre três e dez salários mínimos, ou seja, aos setores de renda média e média baixa. ${ }^{1}$ No Brasil, esse segmento ganhou expressividade, sobretudo, a partir de 2006, quando uma injeção de recursos públicos e privados alavancou a produção de moradias pelo mercado.

O processo de estabilização da economia brasileira, iniciado no Plano Real, consolidou-se nos anos 2000 e repercutiu em crescimento econômico e num aumento considerável do poder de consumo da população, em especial, seus setores médios. ${ }^{2}$ Ao mesmo tempo, o país passou a integrar, mais fortemente, às operações do mercado financeiro mundial, mesmo que, como ressalta Paulani (2008), numa condição de "servidão financeira" em relação à "cabine de comando do capitalismo contemporâneo".

Por um lado, esse crescimento do poder de consumo possibilitou o aumento do número de sujeitos passíveis de obterem créditos, dentre eles, o habitacional. Por outro, essa faixa de consumo foi "descoberta" pelas grandes empresas construtoras e incorporadoras. E esse consumo foi incentivado pelo poder público via crédito habitacional, potencializado pela entrada de capital financeiro nessas grandes empresas. ${ }^{3}$

No âmbito do Estado, a "nova" política nacional de habitação elaborada em 2004 pelo primeiro governo de Luiz Inácio Lula da Silva (2003-2006), visava am-

1 Segundo dados da Embraesp, publicados em matéria do jornal O Estado de São Paulo, entre 2005 e 2009, os lançamentos de imóveis para a "baixa renda" mais do que triplicaram na Região Metropolitana de São Paulo (RMSP), ocorrendo um aumento de $350 \%$. Cf. Pacheco (2010).

2 Alguns autores têm atribuído o crescimento da assim considerada "nova classe média" ou a "classe C" ao aumento da geração privada de trabalho (criação de empregos formais) e do salário mínimo e, em menor grau, aos programas de transferência de renda (como é o caso do Bolsa Família). Cf. Neri (2008).

3 Sobre a atuação das empresas construtoras e incorporadoras financeirizadas no segmento econômico, ver: Shimbo (2010); Castro e Shimbo (2010). 
pliar maciçamente os recursos de fundos públicos e semi-públicos para os financiamentos habitacionais e arregimentar outros fundos para esse fim, na perspectiva de aumentar a produção subsidiada de habitação (para as faixas de menor renda) e de fomentar o mercado privado de habitação (Brasil, 2004).

Como resultados dessa política, por um lado, houve um aumento exponencial nos valores de financiamento habitacional contratados pelo Sistema Financeiro Habitacional (SFH), contando com recursos do Fundo de Garantia do Tempo de Serviço (FGTS) e do Sistema Brasileiro de Poupança e Empréstimo (SBPE). Em 2003, quando se iniciou o primeiro governo Lula, o valor total contratado pelo SFH era de aproximadamente cinco bilhões de reais; em 2008, na metade do segundo governo, esse valor foi multiplicado por oito, excedendo quarenta bilhões de reais. Em 2009, o governo federal formalizou o incentivo à produção privada de moradias a lançar o Programa "Minha Casa, Minha Vida" (PMCMV), com a meta de construir um milhão de unidades habitacionais, injetando um montante de recursos ainda maior do que nas linhas de financiamento anteriores. Em 2011, na segunda versão do programa, a promessa foi de mais dois milhões de unidades. ${ }^{4}$

Outras medidas regulatórias também favoreceram as atividades imobiliárias e o setor da construção civil, como, por exemplo, relacionadas à segurança jurídica na transação de imóveis e à desoneração de impostos. ${ }^{5} \mathrm{O}$ conjunto total das estratégias econômicas e políticas adotadas pelo governo federal favoreceu, em grande medida, o forte aquecimento do mercado habitacional no Brasil. A Região Metropolitana de São Paulo (RMSP) não ficou imune a esse processo: entre 2006 e 2010 , houve um acentuado aumento no número de lançamentos residenciais, superando todos os recordes anteriores desde a década de 1980. Segundo dados da Empresa Brasileira de Estudos do Patrimônio (Embraesp), ${ }^{6}$ os picos desse momento de elevação intensa da produção imobiliária ocorreram em 2007 e 2010 quando, respectivamente, foram lançadas aproximadamente 62 e 67 mil unidades residenciais.

A área central do município de São Paulo também fez parte desse boom imobiliário ocorrido na RMSP. Entre 1991 e 2006, segundo Silva (2006), não foram constatadas alterações significativas na dinâmica imobiliária nos distritos da área central, em relação aos lançamentos de empreendimentos residenciais e comerciais novos. Até então, ainda de acordo com a autora, nenhum dos instrumentos urbanísticos

\footnotetext{
Sobre o PMCMV, ver: Rolnik e Nakano (2009); Fix e Arantes (2009) e Shimbo (2010).

Resumidamente, ao longo do período entre 2004 e 2006, as medidas regulatórias que estimularam diretamente a produção de habitação via mercado foram: a) estímulo ao financiamento imobiliário, reduzindo os juros pagos aos bancos sobre depósitos não utilizados para financiamento dentro do SFH e exigindo que, no mínimo, $65 \%$ dos depósitos em contas de poupança sejam utilizados para esse fim; b) simplificação e intensificação da aplicação das leis de reintegração de posse de propriedade residencial no caso de inadimplência (alienação fiduciária); c) diminuição do IPI (Imposto sobre Produtos Industrializados) sobre certos insumos e materiais de construção; d) fomento para a securitização de recebíveis imobiliários através da isenção de imposto de renda sobre ganhos financeiros advindos dessa transação; e) aumento da segurança de empreendedores através da disponibilização de garantias sobre propriedade e de compradores através do regime tributário especial (Shimbo, 2010).

6 Segundo Marques (2005), "a Embraesp é uma empresa que atua desde 1977, fazendo acompanhamento regular da dinâmica imobiliária, cadastrando informações de todos os empreendimentos verticais e horizontais que tenham sido objeto de propaganda em jornais, revistas, panfletos, assim como os aprovados pela Secretaria de Habitação do município de São Paulo" (Marques, 2005, p. 218).
} 
voltados à atração de empreendimentos imobiliários privados na área central teve o efeito esperado em relação aos objetivos esperados. Entretanto, entre 2007 e 2010, houve um ciclo de elevação de oferta desses empreendimentos e mudanças quanto aos tipos e preços dos produtos imobiliários nessa área.

Como se caracterizam os recentes lançamentos residenciais na área central? Quais os fatores que levaram o mercado imobiliário a investir nessa área? Qual a relação entre as estratégias do poder público, em seus diferentes níveis de planejamento e de intervenção nessa área, e a atuação do mercado?

Partindo dessas questôes, este artigo procura, num primeiro momento, analisar as estratégias adotadas pelo governo municipal para favorecer a atuação do mercado imobiliário na área central, dentro desse contexto nacional de estímulos à produção privada de moradias. Num segundo momento, apresenta o levantamento dos empreendimentos residenciais lançados na área central de São Paulo a partir da base de dados da Embraesp, realizado dentro do escopo do projeto de pesquisa "Edificação e Desenho Urbano com adensamento e qualidade ambiental: habitação de interesse social na recuperação de áreas urbanas degradadas".

\section{Estratégias do governo municipal para a atração da iniciativa privada na área central}

Na cidade de São Paulo, a identificação de áreas "degradadas" localizadas na região central emerge como uma questão que precisava ser enfrentada pelo poder público municipal durante a década de 1970 , a partir da constatação da diminuição do uso habitacional e do aumento dos setores de comércio e serviços. Como destaca Diogo (2004), os problemas identificados nesse período se referiam: à grande oferta de edifícios de uso múltiplo, ao mesmo tempo em que um número considerável de empresas se deslocava do centro para outras localidades; aos congestionamentos viários; à excessiva concentração de funções; e a um "processo de degradação" associado à perda de população de rendas média e alta.

Diversos autores vêm destacando que a construção do discurso sobre a "degradação" e sobre a sua solução, as iniciativas de "revitalização", "requalificação" ou "reabilitação", está em direta relação com a consolidação real de uma "popularização" do centro, tanto em termos de suas atividades (sobretudo, comércio e serviços), quanto de seus moradores. ${ }^{8}$ Ou seja, grande parte das iniciativas tomadas tinha como interesse subjacente ou explícito, trazer de volta as camadas de renda média e alta, procurando reverter a constituição de um centro que atendia, primordialmente, as camadas de renda mais baixa. Em grande medida, a problemática da "revitalização" da área central emergia intrinsecamente relacionada à questão habitacional.

7 Este projeto é financiado pela Coordenação de Aperfeiçoamento de Pessoal de Nível Superior (CAPES/Brasil), entre 2009 e 2013, no âmbito do Programa Nacional de Pós-Doutorado (PNPD), numa parceria entre o Laboratório de Conforto Ambiental e Eficiência Energética (LABAUT) e o Laboratório de Habitação e Assentamentos Humanos (Labhab), ambos da Faculdade de Arquitetura e Urbanismo, da Universidade de São Paulo (FAU/USP).

8 Ver: Tsukumo (2007), Motisuke (2008), Cymbalista et al. (2008), Kara-José (2010). 
Ainda na década de 1970, foram propostos planos, como o "Projeto Centro" (1973-1975) e o "Plano Integrado da Área Central" (1975-1979), que continham tanto um diagnóstico da situação da área central quanto uma problematização da ideia elitista de degradação e de revitalização. Entretanto, a prática implementada priorizou justamente a recuperação de edifícios e de áreas com forte conteúdo simbólico para a elite tradicional paulistana, seguindo a tendência das "cidades de primeiro mundo", como por exemplo, a estratégia de se restringir a circulação de automóveis e de se criar ruas de pedestres.

De todo modo, como destaca Motisuke (2008), o Plano Integrado foi o primeiro documento a problematizar e relativizar o conceito de "deterioração" e, mesmo que de forma embrionária, estava presente a ideia de se aplicar recursos públicos nos melhoramentos urbanos como forma de atrair investimentos privados - prática que vai ser corrente nos anos $1990 \mathrm{e}$, principalmente, 2000.

Durante a década de 1980, não foram propostos projetos urbanos que tratassem a área central em seu conjunto, com exceção de alguns programas habitacionais, já na passagem para os anos 1990, ${ }^{9}$ e da reurbanização do Vale do Anhangabaú.

Portanto, é apenas nos anos 1990 que o centro volta à tona como preocupação do poder público municipal que, a partir daí, passa a elaborar diversos planos, projetos e instrumentos urbanísticos para a área. Dois instrumentos foram aprovados em forma de lei, com objetivo de atrair o interesse do setor privado para investimentos na área central: a Operação Urbana Anhangabaú (Lei no 11.090/91) e a Operação Urbana Centro (Lei no 12.349/97). De acordo com Silva (2004), ambas as operações não despertaram o interesse esperado, resultando em poucas ações concretizadas.

O primeiro projeto mais abrangente foi o Procentro (Programa "Requalificação Urbana e Funcional do Centro de São Paulo”, 1993-2000), quando se iniciou a ideia de contrair empréstimo internacional para intervenção na área central. Revitalizar a área significava aqui potencializar a dinâmica econômica e imobiliária local, por meio da atração de investimento privado e de atividades terciárias consideradas de "ponta". Essa estratégia de se combinar requalificação do território, atração da iniciativa privada e focalização de investimentos era consoante com a visão do Banco Interamericano de Desenvolvimento (BID), a quem se solicitou financiamento, e da Associação Viva o Centro (AVC), que colaborou na elaboração do programa - inclusive essa forte influência do agente financiador e de uma organização não-governamental foi uma novidade do arranjo institucional trazida pelo plano. Como destacam Cymbalista, Tsukumo, Menegon e Brose (2008), o papel da AVC foi essencial para a consolidação da ideia dominante de revitalização de áreas centrais, pautada pelos princípios de gestão urbana neoliberal. O ideário que sustentava essas estratégias tinha como referência os grandes projetos de revitalização em Paris, Barcelona, Londres, Boston e Nova Iorque.

9 Durante a década de 1980, a partir da entrada dos movimentos sociais de moradia na pauta de discussões sobre a produção da cidade na gestão municipal de Luiza Erundina (1989-1992), houve o primeiro programa municipal de habitação social com foco no centro, promovido pela Secretaria Municipal de Habitação (Sehab), o "Programa de Recuperação de Cortiços". Ver: Tsukumo (2007) e Silva (2006). 
Em 2003, o financiamento do BID foi aprovado dentro de uma nova proposta, o Programa "Ação Centro", cujo conteúdo técnico era composto de 130 ações, agrupadas em cinco eixos: I) Reversão da desvalorização imobiliária e recuperação da função residencial; II) Transformação do perfil econômico e social; III) Recuperação do ambiente urbano; IV) Transporte e circulação; V) Fortalecimento institucional do município.

O resultado foi um programa bastante heterogêneo, tanto técnico quanto simbolicamente, que buscou conciliar projetos de várias secretarias municipais para a área central e acabou por misturar princípios de "gestão urbana empresarial", como queria o BID, e "diversidade e inclusão social", como pautavam os movimentos por moradia no centro. Entretanto, foi entre 2001 e 2004 que se implementaram diagnósticos e projetos de habitação de interesse social na área central, sobretudo relacionados à locação social - uma novidade no contexto brasileiro e à reforma de edifícios desocupados. ${ }^{10}$ Também foi nesse momento que se iniciou a ação do governo estadual em relação à recuperação de cortiços e de produção de novas unidades, em parceria com o BID mais uma vez. ${ }^{11}$

Paralelamente, foi elaborado o Plano Diretor de São Paulo (PDE, 2002) que definiu alguns instrumentos para facilitar e promover a Habitação de Interesse Social (HIS) e também a Habitação de Mercado Popular (HMP). O Plano definiu as especificações de cada uma das modalidades, como detalharei no item seguinte, e os perímetros para a produção de HIS e HMP, delimitando-se as Zonas Especiais de Interesse Social (ZEIS), no caso da área central, denominadas como ZEIS $3 .{ }^{12}$

Os incentivos ao mercado imobiliário para viabilizar a produção habitacional nestas áreas se referiram à outorga onerosa gratuita, que possibilitava um coeficiente de aproveitamento maior do que em outras zonas da cidade, sendo necessário respeitar a porcentagem de $40 \%$ para HIS, $40 \%$ para HMP e $20 \%$ de uso livre (não residencial), num terreno maior que $500 \mathrm{~m}^{2}$. Entretanto, como destaca Caldas (2009), apesar dessa vantagem das ZEIS, o processo de aprovação legal na prefeitura é mais complexo, demandando um maior período de tempo para concretização do empreendimento. Até 2005, como destaca Silva (2006), as potencialidades das ZEIS-3 não haviam sido exploradas pelo mercado, somente em uma delas houve

10 Cito aqui o programa "Morar no Centro", que integrava o "Ação Centro", ao qual se vinculava o Programa de Arrendamento Residencial (PAR) - Reforma, dentro de um convênio entre o poder público municipal e a Caixa Econômica Federal. Ver: Tsukumo (2007) e Silva (2006).

11 Refiro-me ao Programa de Atuação em Cortiço (PAC), promovido pela Companhia de Desenvolvimento Habitacional e Urbano do Estado de São Paulo (CDHU), que se iniciou mais precisamente em 1998 e ainda se encontravam em andamento em 2012. Ver: Denizo (2007).

12 As ZEIS 3 são definidas no Plano Diretor Estratégico (2002) conforme o Art. 171: "As Zonas Especiais de Interesse Social - ZEIS são porçōes do território destinadas, prioritariamente, à recuperação urbanística, à regularização fundiária e produção de Habitações de Interesse Social - HIS ou do Mercado Popular - HMP definidos nos incisos XIII e XIV do artigo 146 desta lei, incluindo a recuperação de imóveis degradados, a provisão de equipamentos sociais e culturais, espaços públicos, serviço e comércio de caráter local, compreendendo: [...] III - ZEIS 3 - áreas com predominância de terrenos ou edificações subutilizados situados em áreas dotadas de infraestrutura, serviços urbanos e oferta de empregos, ou que estejam recebendo investimentos desta natureza, onde haja interesse público, expresso por meio desta lei, dos planos regionais ou de lei especifica, em promover ou ampliar o uso por Habitação de Interesse Social - HIS ou do Mercado Popular - HMP, e melhorar as condiçōes habitacionais da população moradora”. (PMSP/SEMPLA, 2002). 
a implementação de um empreendimento habitacional, integrando HIS e HMP, localizado no Bairro da Luz.

Nos projetos urbanos que se seguiram após 2005, como por exemplo o Procentro 2005, foram priorizadas ações destinadas claramente a impulsionar os empreendimentos de iniciativa privada. Foram eliminados os componentes que estavam, de alguma forma, relacionados com a permanência da população de baixa renda, inclusive melhorias no transporte público, além dos empreendimentos de habitação de interesse social. A tônica geral do projeto era a tentativa de reverter o processo em curso de popularização do centro (Kara-José, 2010). Foi nesse contexto que se concebeu o Projeto "Nova Luz", em 2009, pelo poder público municipal, bastante alardeado na mídia.

Para tanto, foi aprovada uma Concessão Urbanística na área do Projeto, instrumento já previsto no Plano Diretor que, segundo Kara-José (2010), tornou mais explícita a aproximação entre política pública e mercado imobiliário. Isso porque, ainda segundo a autora, a Concessão autoriza o Poder Executivo a delegar à iniciativa privada a realização de obras de urbanização ou reurbanização, inclusive, loteamento, reloteamento, demolição, reconstrução e incorporação de conjuntos de edificações — além de poder utilizar instrumentos jurídicos, tais como o direito de preempção, o consórcio imobiliário, a concessão real de uso, etc. Nesse sentido, os empresários são responsáveis pela implantação de um plano urbanístico, cujas diretrizes são definidas pela Prefeitura e, em contrapartida, podem ficar com os lucros da revenda ou da exploração dos imóveis beneficiados depois da reurbanização. A aprovação dessa lei foi objeto tanto de polêmica no judiciário quanto de manifestações do setor comercial do bairro da Santa Ifigênia (Cymbalista et al., 2008; Kara-José, 2010).

Apesar desses instrumentos de política urbana, o trabalho recente de Beatriz Kara-José (2010) argumenta que as dinâmicas de uso do espaço, entre 1990 e 2010, não decorreram diretamente de um projeto público para o centro, mas sim das iniciativas pulverizadas do mercado imobiliário, atraídas pela oportunidade de localização dos empreendimentos na área central. A autora verifica a ampla consolidação do perfil de renda baixa e média baixa no centro, configurando uma "popularização dos residentes" e também uma "popularização dos empregos." ${ }^{13}$

Além disso, os primeiros dados do Censo de 2010 mostram que muitos dos distritos centrais tiveram crescimento da população residente superior à média do município e da RMSP como um todo. Enquanto a taxa de crescimento da população total residente no município de São Paulo, entre 2000 e 2010, foi de 8,1\%, e a da RMSP foi de 10,4\%; distritos localizados na área central, como Brás e Pari apresentaram uma taxa em torno de 19\%; Sé, 17\%; República, 20\%; chegando a 29\% no Cambuci e 27\% no Bom Retiro (Instituto Brasileiro de Geografia e Estatística [IBGE], 2011).

13 A partir dos anos 2000, houve mudanças significativas em relação à composição dos tipos de empregos localizados no Centro, entre as quais, Kara-José (2010) destaca: consolidação do Centro como local de maior densidade de empregos formais do setor de call center do município; centro dos órgãos do poder público municipal e estadual; e a progressiva instalação de instituições privadas de ensino superior. Essas alterações significaram um crescimento do emprego nas atividades que envolvem mão de obra pouco qualificada (vigilância, agenciamento de mão de obra, serviços temporários e processamento de dados). 


\section{A atuação do mercado na produção de habitação na área central}

No bojo dessa popularização e do aumento de residentes na área central, vieram iniciativas do mercado para aumentar a oferta de moradia para os setores de renda média e média baixa. Kara-José (2010) identificou tanto novos tipos de empreendedores imobiliários especializados na reforma de edifícios para a oferta de apartamentos para essas classes, quanto aqueles mais tradicionais, que se voltaram para a construção de novos empreendimentos.

Para caracterizar esses novos empreendimentos, em especial aqueles pertencentes ao segmento econômico, este trabalho traz os resultados do levantamento realizado dentro da extensa base de dados da Embraesp, a partir de critérios de seleção específicos. O primeiro deles diz respeito ao período de análise: foi adotada a primeira década dos anos 2000 (2001-2010), a fim de atualizar os dados já levantados em pesquisas anteriores (entre elas destaco aquela coordenada por Silva, 2006) e de compreender, no âmbito federal, os dois governos Lula (2003-2010) e, municipalmente, à passagem da gestão de Marta Suplicy (2001-2004) à de Serra-Kassab (2004-2008) e, recentemente, à de Gilberto Kassab (2009-2012).

O segundo critério procurou delimitar territorialmente o universo da pesquisa. A abrangência da área central de São Paulo não é definida de modo preciso entre os diversos autores, tampouco nas políticas públicas. ${ }^{14}$ No presente levantamento, foram escolhidos os setores fiscais inseridos nos seguintes treze distritos: Barra Funda, Bela Vista, Belém, Bom Retiro, Brás, Cambuci, Consolação, Liberdade, Mooca, Pari, República, Santa Cecília e Sé. Para além dessa discussão de quais distritos compóem ou não a área central, o importante para a presente pesquisa é trabalhar com áreas urbanas consolidadas, com oferta de infraestrutura, serviços e empregos, e que apresentam certo grau de desvalorização imobiliária, de evasão da população de renda alta e de abandono da atuação do poder público (em inglês, as derelict areas).

O terceiro e último critério diz respeito à caracterização dos imóveis que pertencem ao segmento econômico que, em grande medida, corresponde à Habitação de Mercado Popular (HMP), assim definida no Plano Diretor de São Paulo (2002): unidades com até 2 sanitários, até 1 vaga de garagem e área útil de no máximo $70 \mathrm{~m}^{2}$, podendo ser de promoção pública ou privada, destinada a famílias com renda igual ou inferior a 16 SM $[\mathrm{R} \$ 8.160,00]$ ou capacidade de pagamento a ser definida em lei específica (Silva, 2006, p. 110). Além disso, foi agregado mais um filtro nessa caracterização, relacionado ao preço das unidades residenciais ofertadas, que está diretamente imbricado na capacidade de pagamento do consumidor. Para tanto, foi adotado o teto máximo de $\mathrm{R} \$ 4.000,00 / \mathrm{m}^{2} /$ área útil, que corresponderia a uma

14 Tsukumo (2007) considera Centro ou Área Central de São Paulo, o território correspondente à Subprefeitura da Sé e áreas envoltórias, principalmente as adjacentes. Seria os distritos República, Sé, Bela Vista, Consolação, Santa Cecília, Bom Retiro, Pari, Brás, Cambuci, e parte de Belém e Mooca, não considerando limites rígidos. Kara-José (2010) considera a região central como aquela formada pelo Centro (distritos Sé e República) e pelo conjunto de distritos a ele limítrofes (Santa Cecília, Bom Retiro, Pari, Brás, Cambuci, Liberdade, Bela Vista e Consolação). Silva (2006) considera uma área um pouco mais ampliada, envolvendo mais três distritos, quais sejam Barra Funda, Belém e Mooca. Os trezes distritos considerados por Silva (2006) correspondem à área de abrangência do Programa "Morar no Centro", já citado, e também ao universo desta pesquisa. 
unidade com preço de até $\mathrm{R} \$ 200.000,00$ com área útil de $50 \mathrm{~m}^{2}$, dentro da faixa do segmento econômico do mercado imobiliário.

Vale destacar que, devido ao modo de apresentação do banco de dados da Embraesp, alguns empreendimentos poderiam até apresentar unidades com preços superiores a $\mathrm{R} \$ 4.000,00$. Entretanto, para quantificar o número de unidades de HMP, foram descartadas aquelas situadas acima dessa faixa de preço; porém, para a análise arquitetônica e urbanística dos empreendimentos, foi considerada a totalidade do mesmo.

Para definir um indexador para a correção monetária dos preços das unidades residenciais, foi adotado o Índice Nacional de Custos da Construção (INCC), na medida em que se trata do índice que pauta o custo da construção civil, os financiamentos habitacionais e, consequentemente, os preços de vendas dos imóveis.

\section{Lançamentos residenciais na RMSP e na área central}

Tomando-se os dados dos números totais de unidades residenciais, lançadas anualmente na RMSP, entre 2001 e 2010, é possível notar um ciclo de elevação da dinâmica imobiliária, sobretudo, a partir de 2006. No total do período analisado, foram lançadas 411.831 unidades, das quais, 27.167 (ou 6,6\%) se localizavam na área central.

Em especial, nos treze distritos aqui analisados, houve um aumento na porcentagem de lançamentos em relação ao total lançado na RMSP, entre os anos de 2004 e 2007, ficando entre 7 e $10 \%$ do total. Em números absolutos, os picos de lançamento na área central foram os anos de 2007 (com 4.375 unidades) e 2010 (4.652 unidades), coincidindo com os picos da RMSP. Enfatizando-se apenas os lançamentos residenciais na área central, é possível notar uma curva ascendente da oferta entre 2001 e 2007, com um declínio entre 2008 e 2009 e uma retomada bastante significativa em 2010. Esses números podem ser visualizados no Gráfico 1 .

Procurando caracterizar o tipo de produto ofertado pelo mercado imobiliário, tanto na RMSP quanto na área central, em relação ao padrão de HMP, nota-se uma tendência de aumento de lançamentos contendo unidades com até 1 vaga de garagem e $70 \mathrm{~m}^{2}$ de área útil, entre 2007 e 2010, em números absolutos. Em especial, além do aumento do número absoluto de unidades, em 2009 e 2010, elevou-se também a proporção entre esse tipo de imóvel em relação ao total de unidades lançadas. Isso quer dizer que, nesses dois anos, quase $65 \%$ do total de unidades residenciais lançadas na RMSP corresponderam a esse padrão tipológico: com até 1 vaga de garagem e $70 \mathrm{~m}^{2}$ de área útil. Vale notar que, entre 2002 e 2008, esse padrão de HMP não ultrapassava $50 \%$ do total de unidades lançadas. Em números absolutos, entre 2002 e 2010, a oferta passou de aproximadamente 10.000 unidades para 44.000.

Essa tendência não ocorreu da mesma maneira na área central, na medida em que não apresentou um crescimento da oferta de unidades com até 1 vaga de garagem e $70 \mathrm{~m}^{2}$ de área útil entre 2007 e 2010, em termos relativos. Em números absolutos, as maiores quantidades de unidades ofertadas nesse padrão ocorreram nos anos de 2007 e 2010, coincidindo com os picos da RMSP. O número total de unidades residenciais lançadas na RMSP e a relação com o número de unidades com até 1 vaga de garagem e $70 \mathrm{~m}^{2}$ de área útil, tanto na RMSP quanto na área central, podem ser vistos no Gráfico 2. 
GRÁFICO 1 | Lançamentos residenciais na RMSP e na área central (2001-2010)

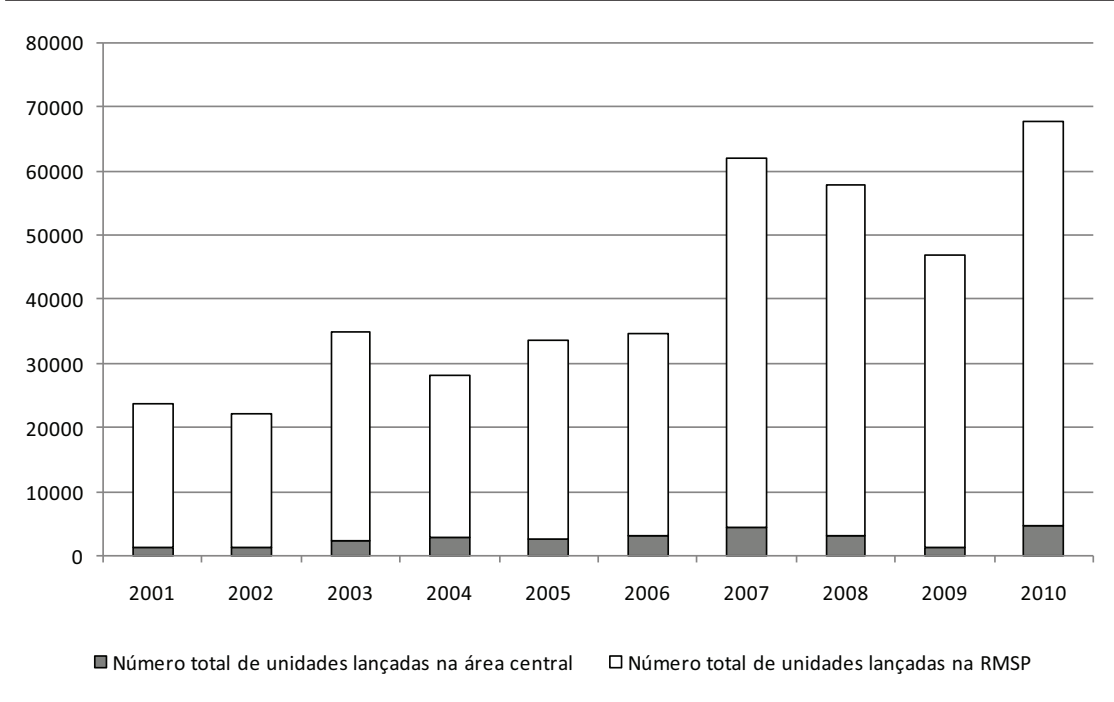

FONTE EMBRAESP, 2001-2010. ELABORAÇÃo PRÓPRIA.

GRÁFICO 2 |Total de lançamentos na RMSP, lançamentos de unidades residenciais com até 1 vaga de garagem e área útil de até $70 \mathrm{~m}^{2}$ na RMSP e na área central (2001-2010)

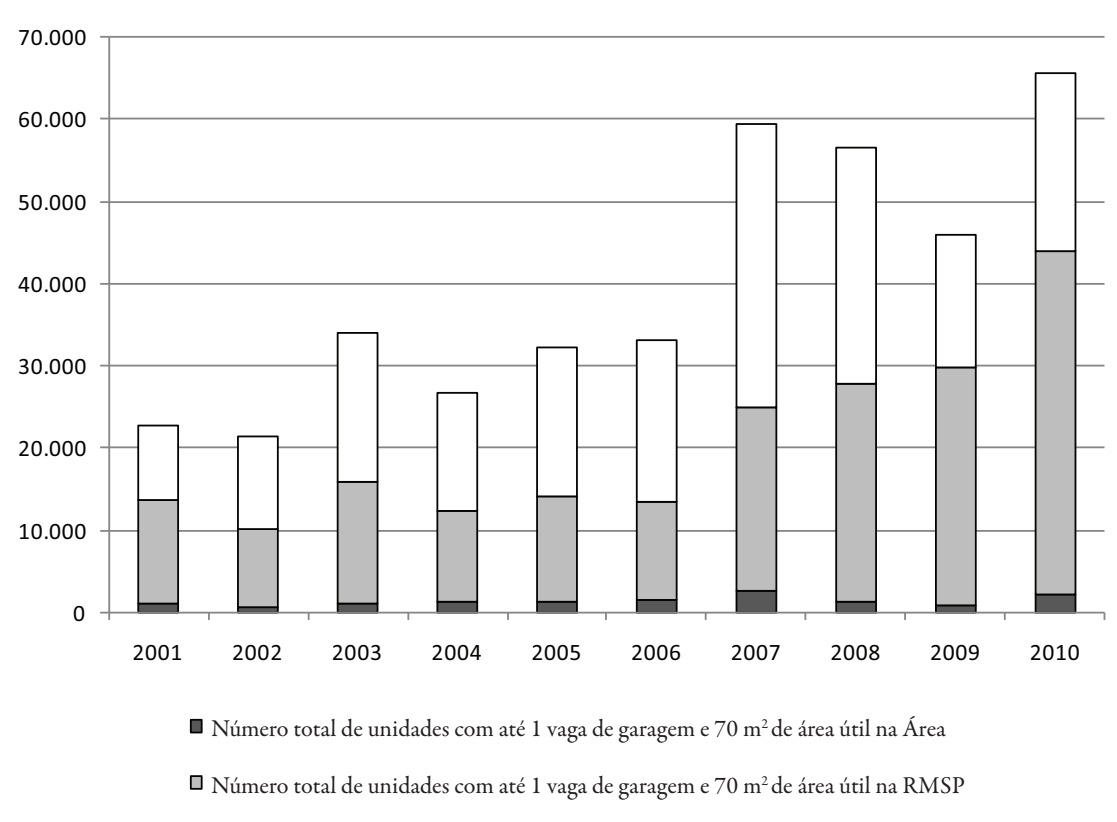

FONTE EMbraesp, 2001-2010. ElaboraÇÃo PRÓPRIA. 


\section{Lançamentos de HMP na área central}

No período entre 2001-2010,38\% das unidades lançadas corresponderam às unidades com até 1 vaga de garagem, até $70 \mathrm{~m}^{2}$ de área útil e preço máximo de $\mathrm{R} \$ 4.000$ / $\mathrm{m}^{2}$, ou seja, 38\% enquadravam-se no padrão de HMP. De modo geral, entre 2001 e 2009, as duas curvas são bastante semelhantes, ou seja, o lançamento de unidades de HMP acompanha as tendências de aumento e de diminuição de lançamentos na área central. Em 2010, esse acompanhamento não ocorreu: do total de unidades lançadas na área central, apenas cerca de 7\% dos lançamentos corresponderam a unidades de HMP, com preço máximo de R\$4.000/ $\mathrm{m}^{2}$. Em 2010, foi ofertado o maior número de unidades residenciais na área central nessa última década, ou seja, 4.652 unidades - entretanto, ainda é muito recente essa alteração e não é possível apontar alguma nova tendência. O Gráfico 3 destaca o número de unidades de HMP em relação ao número total de unidades residenciais lançadas na área central.

GRÁFICO 3 |Lançamentos de unidades residenciais na área central de SP: número total e número de unidades com até 1 vaga de garagem, até $70 \mathrm{~m}^{2} \mathrm{de}$ área útil e preço máximo de $\mathrm{R} \$ 4.000 / \mathrm{m}^{2}$ (2001-2010)

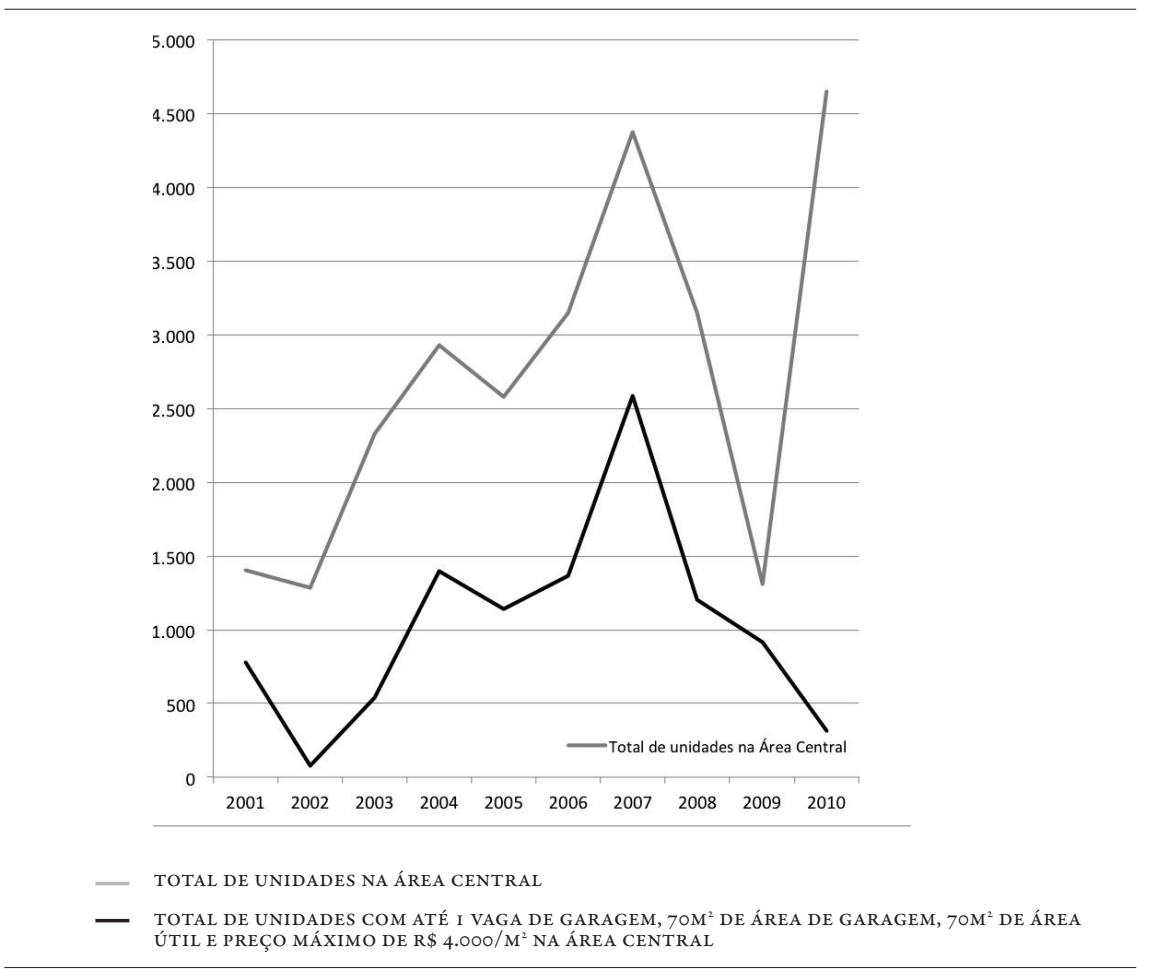

FONTE EMbraesp, 2001-2010. ElaboraÇÃo PRÓPRIA.

Tomando-se como base apenas os dados sobre as unidades residenciais com até 1 vaga de garagem, $70 \mathrm{~m}^{2}$ de área útil e preço máximo de $\mathrm{R} \$ 4.000 / \mathrm{m}^{2}$, pode-se per- 
ceber uma maior concentração da oferta desse tipo de imóvel no quinquênio 20062010. Do total de unidades ofertadas, $41 \%$ ocorreram entre 2001 e 2005 ; e $59 \%$, entre 2006-2010. A Figura 1 indica a localização a grosso modo, dos empreendimentos de HMP com preço de até $\mathrm{R} \$ 4.000,00 / \mathrm{m}^{2}$, lançados entre 2001-2010, na área central de São Paulo.

FIGURA 1 | Localização dos empreendimentos de HMP com preço de até R\$ $4.000,00 / \mathrm{m}^{2}$ na área central (2001-2010)

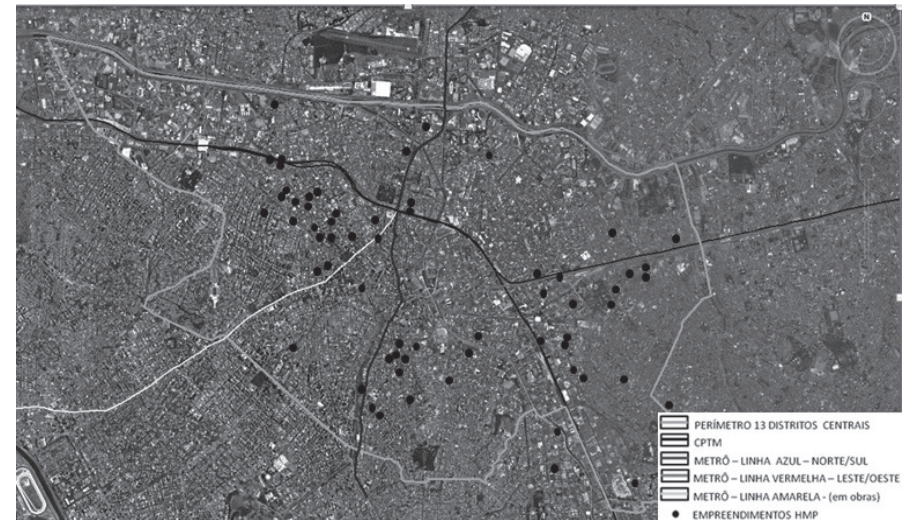

Fonte Embraesp, 2001-2010. ElaboraÇão própria, com a colaboraÇão de Paula Oliveira.

\section{Lançamentos de HMP em ZEIS 3}

Em relação à localização dos empreendimentos de HMP, com preço de até $\mathrm{R} \$ 4.000,00 / \mathrm{m}^{2}$, vale destacar que das 10.317 unidades lançadas entre $2001 \mathrm{e} 2010$, 3.567 (compreendidas em 14 empreendimentos) estavam localizadas em áreas de Zonas Especiais de Interesse Social (ZEIS), em especial naquelas do tipo ZEIS 3, ou seja, $35 \%$ do total. A maior concentração de unidades em ZEIS 3 ocorreu entre 2006 e 2010, quando foram ofertadas 2.673 unidades, correspondendo a $75 \%$ do total do período.

Esses últimos dados mostram uma importante alteração na dinâmica imobiliária na área central. Como já citado anteriormente, até 2005, havia dificuldades de se promover empreendimentos em ZEIS 3 vinculando-se HIS e HMP. Caldas (2009), a partir de dados dos órgãos de aprovação de edificações da Prefeitura Municipal de São Paulo, identificou os números de unidades habitacionais aprovadas para a construção em áreas de ZEIS 3, entre os anos de 2003 e 2007. Até 2005, apenas 404 unidades de HIS haviam sido produzidas pelo mercado imobiliário, 
enquanto o poder público produziu 1.023, e nenhuma unidade de HMP havia sido produzida por ambos. Em 2006 e 2007, a produção privada de HIS foi de 126 unidades e de HMP, 1.075. No conjunto, como destaca Caldas (2009), 53\% da produção habitacional na ZEIS 3 foi realizada pelo mercado imobiliário, sendo o único tipo de ZEIS no município onde a oferta de moradias pela iniciativa privada supera a oferta pública. Para a autora, essa maior atratividade da ZEIS 3 para o mercado pode estar associada à localização das áreas e à oferta de infraestrutura.

Tanto os dados da Embraesp, aqui sistematizados, que se referem a empreendimentos com as características de HMP presentes no Plano Diretor, quanto os dados de Caldas (2009), que dizem respeito aos empreendimentos que foram necessariamente aprovados como HMP, indicam uma tendência de aumento da produção habitacional voltada para o segmento econômico do mercado imobiliário na área central.

\section{Caracterização dos lançamentos de HMP na área central}

Procurando caracterizar os tipos de empreendimentos que se enquadram no padrão HMP que foram ofertados na área central, mais especificamente, entre 2006 e 2010, foram sistematizados os dados referentes ao gabarito das edificações, ao tamanho dos terrenos, aos preços das unidades, ao sistema de financiamento e aos nomes das incorporadoras presentes no banco de dados da Embraesp. A partir de informações disponibilizadas nos sites das incorporadoras e empresas construtoras, foi possível realizar uma análise dos desenhos de implantação e das plantas das unidades de alguns desses empreendimentos.

Em relação ao tamanho dos terrenos dos empreendimentos, $50 \%$ apresenta área total com até $2.000 \mathrm{~m}^{2}$, quase $20 \%$ entre 2.001 e $4.000 \mathrm{~m}^{2}$ e quase $30 \%$ com área acima de $4.001 \mathrm{~m}^{2}$. Em relação ao gabarito, $90 \%$ dos empreendimentos têm acima de dez pavimentos. Do total, vale destacar que $40 \%$ dos empreendimentos apresentam entre 11 e 15 pavimentos; $33 \%$ entre 16 e 20; e $17 \%$ acima de 20 . Há, portanto, uma maior incidência de torres.

Da análise do banco de dados da Embraesp exposta acima, foi possível obter informações mais aprofundadas nos sites de construtoras, incorporadoras e vendedoras, em relação à caracterização arquitetônica e urbanística de empreendimentos com padrão HMP, lançados entre 2006 e 2010.

O tipo "condomínio-clube" está bastante presente nesses lançamentos: ofertam-se áreas de lazer, utilizam-se grandes terrenos, agrupam-se torres, adotam-se estacionamento no térreo e constroem-se muros em todo o perímetro do empreendimento, como pode ser visto nas Figuras 2 e 3. Em termos percentuais, $40 \%$ do total dos empreendimentos apresentam mais de uma torre e $44 \%$ tem estacionamento descoberto no térreo (uma parte ou a totalidade das vagas). Inclusive, a adoção de grandes torres pode ser uma estratégia para compensar a grande área de terreno deixada para estacionamento. 
Analisando-se as plantas das unidades habitacionais é possível observar a oferta de apartamentos com 1, 2 ou 3 dormitórios e área útil entre 32 e $68 \mathrm{~m}^{2}$, o que demonstra uma alta compacidade da área interna - vale a pena destacar que existe a oferta de unidades com 3 dormitórios e $55 \mathrm{~m}^{2}$.

FIGURA 2 Fotos de empreendimentos de HMP com preço de até $\mathbf{R} \$ 4.000,00 / \mathrm{m}^{2}$ em ZEIS 3 (2001-2010).

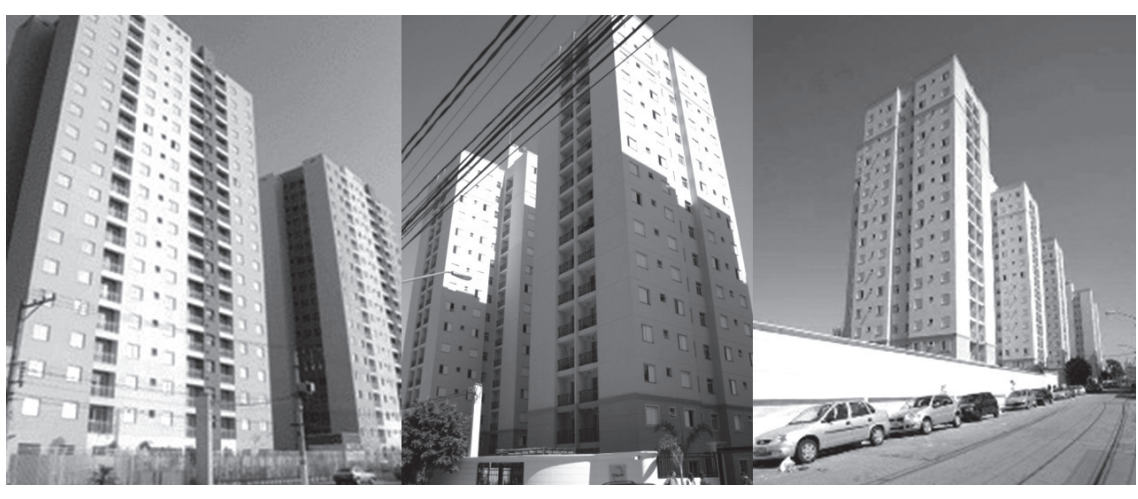

FONTE SITES DAS INCORPORADORAS E CONSTRUTORAS.

FIGURA 3 Exemplos de implantação de empreendimentos de HMP com preço de até $\mathrm{R} \$ 4.000,00 / \mathrm{m}^{2} \mathrm{em}$ ZEIS 3 (2001-2010)
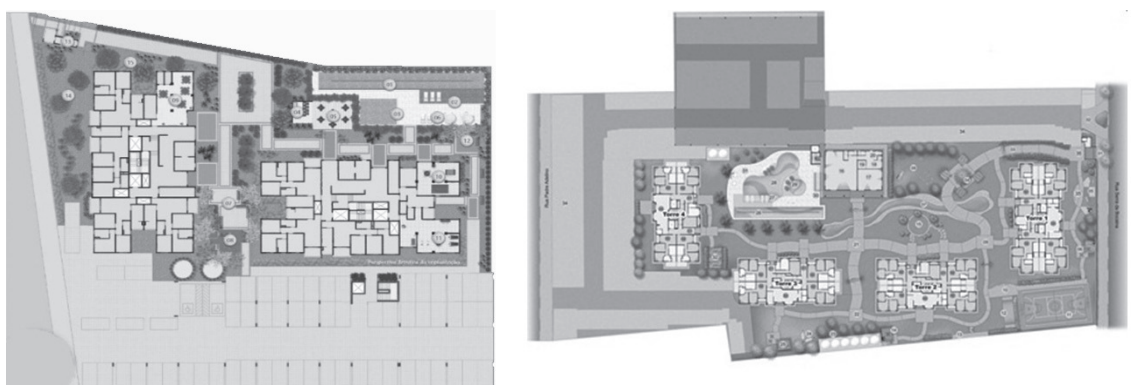

FONTE SITES DAS INCORPORADORAS E CONSTRUTORAS.

Em relação aos preços das unidades ofertadas pelos empreendimentos de HMP, com até $\mathrm{R} \$ 4000,00 / \mathrm{m}^{2}$ de área útil, aproximadamente $50 \%$ das unidades encontram-se na faixa entre $\mathrm{R} \$ 3.0001,00$ e $4.000,00 / \mathrm{m}^{2}$ e apenas $7 \%$ apresentam um preço de até $\mathrm{R} \$ 2.000,00 / \mathrm{m}^{2}$.

Em relação aos agentes do sistema financeiro de cada um dos empreendimentos, os dados da Embraesp separam aqueles financiados pela Caixa Econômica Federal 
(CAIXA) dos demais financiamentos dentro do Sistema Financeiro da Habitação (SFH) - nesses últimos, os dados não indicam o agente operador. Dentre as unidades de HMP na área central, $43 \%$ foram financiadas pela CAIXA.

Em relação aos incorporadores dos empreendimentos de HMP na área central, é possível observar uma diversidade muito grande: há trinta e duas empresas que lançaram unidades entre 2006 e 2010. A incorporadora Atua foi quem mais ofertou unidades desse tipo, contemplando $15 \%$ do total. Em segundo lugar, vem a Goldfarb, com $8 \%$ e, em terceiro, a TPA, com 6\%. Os $71 \%$ restantes estão divididos nas demais 29 empresas. Outro dado importante se refere ao porte dessas incorporadoras: apenas $15 \%$ das unidades foram lançadas por empresas de capital aberto, ou subsidiárias a elas, especificamente, Company, Cyrela, Goldfarb e Cury.

\section{Comparação com a produção do segmento econômico de mercado no Brasil}

As pesquisas qualitativas sobre o segmento econômico do mercado imobiliário na RMSP e no Brasil, desenvolvidas recentemente ${ }^{15}$, indicam que, para atuarem nas faixas de renda média e média baixa, as empresas construtoras precisaram adotar uma produção em escala da habitação. Isso significa desenvolver e implementar uma padronização tipológica e construtiva que se repete em todas as regiões brasileiras onde elas atuam - aliás, a diversificação geográfica foi uma das novidades trazidas pelo segmento. Castro e Shimbo (2011) identificam a consolidação do "padrão econômico", que veio atender os segmentos da população que demandavam a casa própria, em períodos de incremento da atividade setorial, ou seja, no final da década de 1990 e no início dos anos 2000, e que ampliou consideravelmente o mercado residencial no Brasil.

A maioria das empresas segue três tipos básicos: I) o condomínio horizontal, composto de casas térreas ou sobrepostas (em muitos casos, geminadas), com uma vaga de garagem externa e descoberta, com área de lazer comum e arruamento interno, dentro de um perímetro murado; II) o empreendimento vertical contendo edifícios de até cinco pavimentos, sem elevador, com área de lazer reduzida (ou inexistente) e estacionamento no térreo; e III) o empreendimento vertical contendo edifícios acima de cinco pavimentos, com elevador, com área de lazer reduzida (ou inexistente) e estacionamento no térreo. Em particular, na RMSP, há a maior concentração de empreendimentos verticais, acima de oito pavimentos, localizados em áreas menos consolidadas e periféricas (Shimbo, 2010).

Nos três tipos, prevalece a concepção de "condomínio-clube", modelo até então adotado para os empreendimentos de alto-padrão, mesmo que a área de lazer seja bastante restrita e não haja espaços de consumo e de trabalho, como ocorre naqueles voltados para as camadas de renda mais altas. Na maioria dos empreendimentos do segmento econômico, localizados nas capitais e nas cidades do interior do Brasil, o financiamento a clientes ocorre via CAIXA — mais recentemente, concentrado no PMCMV.

15 Destaco os seguintes estudos recentes: Sígolo (2009), Royer (2009), Shimbo (2010), Tone (2010), Moura (2011) e Cardoso (2011). 
Há, portanto, algumas semelhanças e diferenças entre a produção nacional voltada para o segmento econômico e a produção específica de HMP na área central de São Paulo. O padrão urbanístico e arquitetônico é bastante semelhante: grandes glebas, mais de uma torre por empreendimento, ou seja, concentração de um grande número de unidades por empreendimento, com áreas de lazer e estacionamento no térreo. Há uma diferença quanto ao tipo de produto, pois na área central são ofertadas unidades com apenas um dormitório que, por sua vez, não são ofertadas em outras localizações. Em relação ao financiamento, em ambos os casos, trata-se de fontes públicas ou semi públicas, operacionalizadas pela CAIXA.

Uma diferença fundamental diz respeito aos agentes promotores. Enquanto na área central há uma diversidade de empresas construtoras e incorporadoras, na maioria delas de pequeno e médio porte, no segmento econômico, de forma geral, predominam as grandes empresas, em grande parte, de capital aberto. Mesmo assim, as empresas locais parecem seguir a tendência dos produtos imobiliários ofertados pelas grandes empresas.

\section{Questôes finais}

A comparação entre o padrão econômico de habitação que vem sendo ofertado pela iniciativa privada no Brasil, em geral, e os lançamentos de HMP na área central de São Paulo levanta a seguinte questão: como o mercado está conseguindo reproduzir esse padrão, tanto em áreas periféricas de capitais e em cidades do interior, quanto em áreas centrais metropolitanas, onde o preço da terra, teoricamente, tenderia a ser mais elevado?

Apesar da questão fundiária ser bastante complexa e de carecer de pesquisas mais aprofundadas a respeito, algumas pistas para essa resposta podem ser aqui esboçadas e estão relacionadas com as questões de fundo deste artigo.

Há uma imbricação entre a atuação do mercado e as estratégias do poder público que propiciou a recente consolidação do padrão econômico da habitação no Brasil. A liminaridade entre aquela habitação que poderia ser considerada tecnicamente como de "interesse social" e aquela que seria voltada para um "mercado popular" está presente, por exemplo, nos fundos dos financiamentos habitacionais para o segmento econômico. $\mathrm{Na}$ área central, $43 \%$ das unidades de HMP foram financiadas pela CAIXA - acessando, portanto, recursos semi públicos, como é o caso do FGTS operacionalizado por esse banco, para a promoção desses empreendimentos do mercado.

Essa liminaridade também pode ser verificada na área central, em relação à localização dos empreendimentos. É significativo que 35\% das unidades de HMP, com preço de até $R \$ 4.000,00 / \mathrm{m}^{2}$, ofertadas entre 2001 e 2010, estejam localizadas em áreas especiais de interesse social, no caso, em ZEIS 3. Isso pode significar que o mercado está se beneficiando dos incentivos propiciados pela legislação urbanística, que prevê coeficientes maiores de ocupação e outros mecanismos facilitadores para a implementação de habitação popular de mercado e também de habitação de 
interesse social — sendo essa última, mote principal desse tipo de regulamentação. Resta saber se tais empreendimentos de HMP estão casados com aqueles de HIS no mesmo terreno, como prevê o Plano Diretor e os Planos Regionais Estratégicos dos distritos do município - aspectos que não são publicizados pelo poder público.

A invisibilidade dos processos decisórios, a respeito da produção do ambiente construído, está diretamente relacionada à concepção de "cidade-empresa", discutida por Vainer (2011), pautada no modelo de eficiência empresarial para o planejamento urbano, na qual as relações entre interesses privados e Estado se entronizam de tal forma que inviabilizam os responsáveis pela decisão. $\mathrm{O}$ autor analisa essa concepção para o caso do Rio de Janeiro, mas serve também para a área central de São Paulo. Há tanto os mecanismos de atração da iniciativa privada anunciados de forma explícita nos planos, projetos e legislações (mais recentemente, destaca-se a concessão urbanística) para a área central, quanto nas brechas interditas da própria legislação que, muitas vezes, são utilizadas pelo mercado para priorizar seu público preferencial, os setores de renda média e alta - como é o caso da produção de HMP em ZEIS 3 que, teoricamente, se voltariam para o atendimento de setores de baixa renda.

Brindley, Rydin e Stoker (1987) destacam que o tipo "Planejamento de gerenciamento privado" (em inglês, Private-Management Planning), muito próximo da concepção de "cidade-empresa", apresenta as vantagens de destinar recursos, de fontes privadas e públicas, e de agir de modo mais rápido e flexível que os procedimentos tradicionais dos governos locais, porém, com a forte desvantagem de limitar o poder público no processo de decisão e de gestão. Ao analisarem os tipos de planejamento urbano presentes na Inglaterra da década de 1980, os autores concluem que o modelo "empresa" não pode ser considerado como um caminho para renovar áreas abandonadas (derelict areas). A justificativa de que o setor privado tem a habilidade de gerar lucros, por meio de uma gestão eficiente, e de redistribuí-los para benefício dos grupos de baixa renda, não se realiza concretamente. Os estudos de caso analisados por Brindley, Rydin e Stoker (1987) mostraram que o setor privado não é tão efetivo assim, tampouco generoso.

Parece que São Paulo não aprendeu a lição e mantém o modelo empresarial de planejamento para a área central, em plenos anos 2000. Para além dos planos e projetos que identificaram as áreas "degradadas" (lembrando do conceito nebuloso de blight, analisado por Rachel Weber), onde é necessária intervenção pública e privada, o mercado age de forma pulverizada, demolindo edificações e ocupando grandes glebas de áreas consolidadas para reproduzir o padrão econômico da habitação na sua modalidade "condomínio-clube".

Olhando-se do ponto de vista da oferta, a reprodução desse padrão de habitação, tanto em áreas centrais como periféricas, diz respeito, em grande medida, ao processo de financeirização ao qual o mercado imobiliário brasileiro se submeteu desde 2006 - e que impulsionou significativamente a produção habitacional.

No contexto norte-americano analisado por Weber (2002), desde os anos 1970, a mercadoria imobiliária se tornou progressivamente desmaterializada e desterritorializada. $\mathrm{O}$ mercado imobiliário perdeu seu estatuto de ativo distinto e peculiar, 
muito atribuído à questão da propriedade fundiária, tornando-se mais desvinculado do lugar e mais sujeito ao poder do capital global. Talvez possamos pensar nesta chave apontada por Weber (2002): as áreas centrais não podem ser encaradas apenas pela sua especificidade territorial e histórica, que acaba por enquadrá-las numa determinada política urbana de regeneração. O protagonismo do mercado na produção do ambiente construído as insere, necessariamente, nas tendências mais gerais da mercadoria imobiliária e no modelo "empresa" de gestão da cidade. OEURE

\section{Referências bibliográficas}

Bidou-Zachariasen, C. (Coord.). (2006). De volta à cidade: dos processos de gentrificação às políticas de "revitalização" dos centros urbanos. São Paulo: Annablume.

Brasil. Ministério das Cidades. Politica Nacional de Habitação. Brasília: Ministério das Cidades, 2004. Brindley, T., Rydin, Y. \& Stoker, G. (1987). Six styles of planning in practice. In: Remaking Planning: The Politics of Urban Change. Londres: Unwin Hyman.

Caldas, M. N. P. (2009). Os novos instrumentos da politica urbana: alcance e limitações das ZEIS. Tese (Doutorado - Habitat), Faculdade de Arquitetura e Urbanismo, Universidade de São Paulo.

Cardoso, A. (Coord.). (2011). Entre a politica e o mercado: desigualdades, exclusão social e produção da moradia popular na Regiäo Metropolitana do Rio de Janeiro. Relatório de pesquisa, Rio de Janeiro, 2011. In mimeo.

Castro, C. M. P. \& Shimbo, L. Z. (2010). Das cooperativas autofinanciadas às construtoras e incorporadoras de capital aberto: a ampliação do mercado habitacional. Revista Brasileira de Estudos Urbanos e Regionais, 12(1), 53-73.

Castro, C. M. P. \& Shimbo, L. Z. (2011). "Padrão Econômico" da Habitação: Construindo uma Trajetória de Mercado. In: XIV Encontro Nacional da ANPUR, 23 a 27 maio, 2011, Rio de Janeiro [CD-ROM]. RJ. Anais... Rio de Janeiro: ANPUR. Em http://www.anpur.org.br/ site/anais/ena14/ARQUIVOS/GT2-395-83-20101221115533.pdf

Cymbalista, R., Tsukumo, I. T., Menegon, N. M. \& Brose, M. (2008). Politicas públicas para o Centro: controle social do financiamento do BID à Prefeitura Municipal de São Paulo. São Paulo: Instituto Polis.

Denizo, V. (2007). Os produtos da política estadual de habitação na RMSP: elementos para análise de uma politica metropolitana de habitação. Tese (Doutorado - História e fundamentos da Arquitetura e Urbanismo), Faculdade de Arquitetura e Urbanismo, Universidade de São Paulo.

Diogo, E. C. C. (2004). Habitação Social no contexto da reabilitação urbana da Area Central de São Paulo. Dissertação (Mestrado - Planejamento Urbano e Regional), Faculdade de Arquitetura e Urbanismo, Universidade de São Paulo.

Fix, M. \& Arantes, P. F. (2009). Como o governo Lula pretende resolver o problema da habitação Alguns comentários sobre o pacote habitacional Minha Casa, Minha Vida. Correio da Cidadania. Disponível em: http://www.correiocidadania.com.br

Haddad, E. \& Meyer, J. F. P. (2009). Housing Conditions and Income Distribution: Evidence from São Paulo. In: S.V. Lall, M. Freire, B. Yuen, R. Rajack \& J. J. Helluin (Eds.), Urban Land Markets: Improving Land Management for Successful Urbanization. London, New York: Springer. 
Instituto Brasileiro de Geografia e Estatística (IBGE). (2011). Censo 2010: Tabela 1309, população residente por sexo, situação e localização da área. Disponível em: http://www.censo2010. ibge.gov.br/resultados_do_censo2010.php.

Kara-José, B. (2012). A popularização do centro de São Paulo: um estudo de transformações ocorridas nos últimos vinte anos. Tese (Doutorado - Planejamento Urbano e Regional), Faculdade de Arquitetura e Urbanismo, Universidade de São Paulo.

Marques, E. C. L. (2005). A dinâmica imobiliária de incorporação em período recente. In: E. C. L. Marques \& H. Torres (Orgs.), São Paulo: segregação, pobreza urbana e desigualdade social. São Paulo: Ed. Senac.

Motisuke, D. (2008). Reabilitação de áreas centrais: antagonismos e ambiguidades do programa paulistano Ação Centro. Dissertação (Mestrado - Habitat), Faculdade de Arquitetura e Urbanismo, Universidade de São Paulo.

Moura, A. D. S. de. (2011). Novas soluçôes, velhas contradiçôes: a dinâmica cíclica da industrialização em sua forma canteiro. Dissertação (Mestrado), Faculdade de Arquitetura e Urbanismo, Universidade de São Paulo.

Neri, M. C. (Coord.). (2008). A nova classe média. Rio de Janeiro: Fundação Getulio Vargas (FGV)/ Instituto Brasileiro de Economia (IBRE), Centro de Políticas Sociais (CPS).

Pacheco, P. (2010). Baixa renda atropela imóvel de luxo. O Estado de São Paulo, São Paulo, 28 fev. 2010. Economia, p.B8. Em http://m.estadao.com.br/noticias/impresso,baixa-renda-atropela-imovel-de-luxo,517158.htm

Paulani, L. (2008). Brasil delivery: servidão financeira e estado de emergência econômico. São Paulo: Boitempo.

Prefeitura do Município de São Paulo (PMSP)/Secretaria Municipal de Planejamento (Sempla). (2002). Plano Diretor Estratégico do Município de São Paulo - Lei nº 13.430/2002.

Prefeitura do Município de São Paulo (PMSP)/Secretaria Municipal de Planejamento (Sempla). (2004a). Plano Regional Estratégico da Subprefeitura Sé.

Prefeitura do Município de São Paulo (PMSP)/Secretaria Municipal de Planejamento (Sempla). (2004b). Plano Regional Estratégico da Subprefeitura Mooca.

Rocha, M. (2011). No início e por 22 anos, só havia o BNH. O Estado de São Paulo. São Paulo, 13 maio 2011. Economia e Negócios.

Rolnik, R. \& Nakano, K. (2009, março). As armadilhas do pacote habitacional. Le Monde Diplomatique (Brasil), 2(20).

Royer, L. de O. (2009). Financeirização da política habitacional: limites eperspectivas. Tese (Doutorado em Arquitetura e Urbanismo) - Faculdade de Arquitetura e Urbanismo, Universidade de São Paulo, São Paulo.

Shimbo, L. Z. (2010). Habitação Social, Habitação de Mercado: a confluência entre Estado, empresas construtoras e capital financeiro. Tese (Doutorado em Arquitetura e Urbanismo) - Escola de Engenharia de São Carlos, Universidade de São Paulo, São Carlos.

Sigolo, L. M. (2009). O aquecimento recente do mercado formal de moradia no Brasil e seu espelhamento em Diadema. In: XIII Encontro Nacional da ANPUR, Florianópolis, 25 a 29 maio [CD-ROM]. Florianópolis: ANPUR.

Silva, L. O. da. (2004). Decadência e reabilitação do centro de São Paulo. Ação para o Centro de São Paulo [CD-ROM] São Paulo: Empresa Municipal de Urbanização (Emurb); Prefeitura Municipal de São Paulo (PMSP); Centro Brasileiro de Análise e Planejamento (Cebrap); e Centro de Estudos da Metrópole (CEM). 
Silva, H. M. B. (2006). Observatório do uso do solo e da gestão fundiária do centro de São Paulo. Relatório de pesquisa. São Paulo: LABHAB/FAUUSP. Laboratório de Habitação e Assentamentos Humanos (Labhab), Faculdade de Arquitetura e Urbanismo (FAU), Universidade de São Paulo (USP).

Silva, H. M. B. (Coord). (2007). Oportunidades e limites para a produção de habitação social no centro de São Paulo. Relatório de pesquisa. São Paulo: Lincoln Institute of Land Policy.

Smith, N. (2006). A gentrificação generalizada: de uma anomalia local à "regeneração"urbana como estratégia urbana global. In: C. Bidou-Zachariasen, (Coord.), De volta à cidade: dos processos de gentrificação às políticas de "revitalização" dos centros urbanos. São Paulo: Annablume.

Tone, B. B. (2010). Notas sobre a valorização imobiliária em São Paulo na era do capital fictício. Dissertação (Mestrado). Faculdade de Arquitetura e Urbanismo, Universidade de São Paulo, São Paulo.

Tsukumo, I. T. L. (2007). Habitação social no centro de São Paulo: legislação, produção, discurso. Dissertação (Mestrado - Habitat), Faculdade de Arquitetura e Urbanismo, Universidade de São Paulo.

Vainer, C. (2011). Cidade de exceção: reflexões a partir do Rio de Janeiro. . In: XIV Encontro Nacional da ANPUR, 23 a 27 maio, 2011, Rio de Janeiro [CD-ROM]. Rio de Janeiro: ANPUR.

Weber, R. (2002). Extracting value from the city: neoliberalism and urban redevelopment. Antipode, 34(3), 519-540. doi: 10.1111/1467-8330.00253

Zancheti, S. M. (2010). Regeneração urbana na América Latina: os caminhos do financiamento dos projetos. In: I Encontro Nacional da Associação Nacional de Pesquisa e Pós-Graduação em Arquitetura e Urbanismo I Enanparq), Rio de Janeiro (Palácio Gustavo Capanema e Clube de Engenharia), 29 novembro a 3 dezembro. 